\title{
Plasma levels of six carotenoids in nine European countries: report from the European Prospective Investigation into Cancer and Nutrition (EPIC)
}

\author{
Wael K Al-Delaimy ${ }^{1, *}$, Anne Linda van Kappel ${ }^{2}$, Pietro Ferrari ${ }^{1}$, Nadia Slimani ${ }^{1}$, \\ Jean-Paul Steghens ${ }^{3}$, Sheila Bingham ${ }^{4}$, Ingegerd Johansson ${ }^{5}$, Peter Wallström ${ }^{6}$, \\ Kim Overvad ${ }^{7}$, Anne Tiønneland ${ }^{8}$, Tim J Key ${ }^{9}$, Ailsa A Welch ${ }^{10}$,
} $\mathrm{H}$ Bas Bueno-de-Mesquita ${ }^{11}$, Petra HM Peeters ${ }^{12}$, Heiner Boeing ${ }^{13}$, Jakob Linseisen ${ }^{14,15}$, Françoise Clavel-Chapelon ${ }^{16}$, Catherine Guibout ${ }^{16}$, Carmen Navarro ${ }^{17}$, Jose Ramón Quirós ${ }^{18}$, Domenico Palli ${ }^{19}$, Egidio Celentano ${ }^{20}$, Antonia Trichopoulou ${ }^{21}$, Vassiliki Benetou ${ }^{21}$, Rudolf Kaaks ${ }^{1}$ and Elio Riboli ${ }^{1}$

'Unit of Nutrition and Cancer, International Agency for Research on Cancer (IARC), 150 Cours Albert Thomas, 69372 Lyon Cedex 08, France: ${ }^{2}$ Current address: CRYO BIO SYSTEM, Paris, France: ${ }^{3}$ Biochemistry Laboratory C, Hôpital Edouard Herriot, Lyon, France: ${ }^{4}$ MRC Dunn Human Nutrition Unit, Cambridge, UK: ${ }^{5}$ Department of Odontology Cariology, Umeå University, Umeå, Sweden: ${ }^{6}$ Department of Medicine, Surgery \& Orthopaedics, Lund University, Malmö, Sweden: ${ }^{7}$ Department of Epidemiology and Social Medicine, University of Aarhus, Aarhus, Denmark: ${ }^{8}$ Institute of Cancer Epidemiology, Danish Cancer Society, Copenhagen, Denmark: ${ }^{9}$ Cancer Research UK, Oxford, UK: ${ }^{10}$ Strangeways Research Laboratory, University of Cambridge, Cambridge, UK: ${ }^{11}$ National Institute of Public Health and the Environment, Bilthoven, The Netherlands: ${ }^{12}$ Julius Center for Health Sciences and Primary Care, University Medical Center, Utrecht, The Netherlands: ${ }^{13}$ German Institute of Human Nutrition, PotsdamRehbrücke, Germany: ${ }^{14}$ Former address: German Cancer Research Center, Heidelberg, Germany: ${ }^{15}$ Current address: Technical University of Munich, Freising-Weihenstephan, Germany: ${ }^{16}$ INSERM U 521, Institut Gustave Roussy, Villejuif, France: ${ }^{17}$ Department of Epidemiology, Health Council of Murcia, Murcia, Spain: ${ }^{18}$ Regional Office of Public Health of Asturias, Oviedo, Spain: ${ }^{19}$ Molecular \& Nutritional Epidemiology Unit, CSPO, Scientific Institute of Tuscany, Florence, Italy: ${ }^{20}$ Department of Clinical \& Experimental Medicine, University of Naples Federico II, Naples, Italy: ${ }^{21}$ University of Athens Medical School, Athens, Greece

Submitted 9 September 2003: Accepted 7 January 2004

\begin{abstract}
Background: In addition to their possible direct biological effects, plasma carotenoids can be used as biochemical markers of fruit and vegetable consumption for identifying diet-disease associations in epidemiological studies. Few studies have compared levels of these carotenoids between countries in Europe.

Objective: Our aim was to assess the variability of plasma carotenoid levels within the cohort of the European Prospective Investigation into Cancer and Nutrition (EPIC). Methods: Plasma levels of six carotenoids $-\alpha$-carotene, $\beta$-carotene, $\beta$-cryptoxanthin, lycopene, lutein and zeaxanthin - were measured cross-sectionally in 3043 study subjects from 16 regions in nine European countries. We investigated the relative influence of gender, season, age, body mass index (BMI), alcohol intake and smoking status on plasma levels of the carotenoids.

Results: Mean plasma level of the sum of the six carotenoids varied twofold between regions $\left(1.35 \mu \mathrm{moll}^{-1}\right.$ for men in Malmö, Sweden vs. $2.79 \mu \mathrm{moll}^{-1}$ for men in Ragusa/Naples, Italy; $1.61 \mu \mathrm{moll}{ }^{-1}$ for women in The Netherlands vs. $3.52 \mu \mathrm{moll}^{-1}$ in Ragusa/Naples, Italy). Mean levels of individual carotenoids varied up to fourfold ( $\alpha$-carotene: $0.06 \mu \mathrm{moll}^{-1}$ for men in Murcia, Spain vs. $0.25 \mu \mathrm{moll}^{-1}$ for vegetarian men living in the UK). In multivariate regression analyses, region was the most important predictor of total plasma carotenoid level (partial $R^{2}=27.3 \%$ ), followed by BMI (partial $R^{2}=5.2 \%$ ), gender (partial $R^{2}=2.7 \%$ ) and smoking status (partial $R^{2}=2.8 \%$ ). Females had higher total carotenoid levels than males across Europe. Conclusions: Plasma levels of carotenoids vary substantially between 16 different regions in Italy, Greece, Spain, France, Germany, the UK, Sweden, Denmark and The Netherlands. Compared with region of residence, the other demographic and lifestyle factors and laboratory measurements have limited predictive value for plasma carotenoid levels in Europe.
\end{abstract}

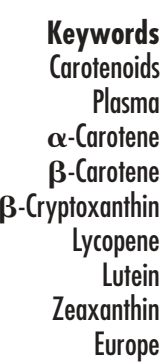


Carotenoids are natural pigments generally found in fruit and vegetables. They can be synthesised by plants but not by animals and humans, and plant foods are therefore the primary source for humans ${ }^{1}$. Although carotenoids can be used as biomarkers of specific nutrients and their relationship to diseases ${ }^{2-4}$, they are also known antioxidants 5,6 . Thus they are of interest in a variety of human diseases whose aetiology is thought to involve oxidative damage, including cancer ${ }^{7,8}$. The data on the relationship of blood levels of these carotenoids with human disease are not conclusive because of different study designs and methodologies, including different laboratory methodologies $^{8-11}$. At least 40 different carotenoids are present in food $^{12}$ and more than 10 of them have been identified in blood $^{13-15}$. However, little is known about the population levels of these compounds and, to our knowledge, only one published study has compared serum carotenoid levels between European regions ${ }^{16}$. Olmedilla et al. reported significant differences in serum carotenoid levels among five European countries: France, Ireland, Spain, the UK (Northern Ireland) and The Netherlands ${ }^{16}$. That study was well-controlled in terms of laboratory analyses, the recruitment of volunteers and their baseline data; however, the study was relatively small, with only 349 participants from the five countries, and did not assess possible predictors of carotenoids in participating centres.

In the European Prospective Investigation into Cancer and Nutrition (EPIC), blood samples were collected from 386080 healthy subjects, which makes it one of the largest biorepositories in the world. We report here results on plasma levels of six carotenoids from a large crosssectional sub-sample within the EPIC cohort, including 3043 men and women from 16 geographical areas in nine European countries. We also examine the influence of region, gender, season, age, body mass index (BMI), alcohol intake, smoking status and various laboratory parameters on the plasma carotenoid levels.

\section{Subjects and methods}

EPIC is a multi-centre prospective cohort study investigating the relationship between diet, nutritional and metabolic characteristics, various lifestyle and environmental factors, and the risk of cancer, cardiovascular disease, diabetes and other chronic diseases ${ }^{17}$. Twentythree research centres in 10 European countries are participating in the EPIC study, which is co-ordinated by the International Agency for Research on Cancer (IARC) in Lyon, France. Collection of data and blood samples started in 1992 and follow-up is planned for at least 15 years. EPIC is unique in that it combines the largest and most diverse number of subjects with information on their diet and lifestyle, reported via questionnaires, and blood samples collected from most of them. Samples are stored in order to compare exposures of interest between individuals who develop cancer during follow-up and those who do not develop these cancers. One of the important features is that the blood samples were collected using the same protocol and preserved at very low temperatures.

\section{Study population}

In this analysis, 16 geographical areas (regions) were designated by grouping centres within the EPIC study: France (Paris and surroundings), Florence (central Italy), Varese/Turin (northern Italy), Ragusa/Naples (southern Italy), northern Spain (San Sebastian, Pamplona, Oviedo), Granada (southern Spain), Murcia (south-eastern Spain), Cambridge (subjects living in Norfolk), Oxford centre (vegetarians living throughout the UK), The Netherlands (including subjects from Utrecht and Bilthoven), Athens in Greece, Heidelberg (south-west Germany), Potsdam (former East Germany), Malmö (southern Sweden), Umeå (northern Sweden) and Denmark (including subjects from Aarhus and Copenhagen). Sub-samples of 100 women and 100 men in each of these regions were randomly selected from a representative calibration sample of $7 \%$ of the EPIC cohort $^{18}$, for whom a complete set of 14 aliquots of serum, plasma, buffy coat and red blood cells was stored at IARC, Lyon. The selection followed a stratified sampling scheme with 50 subjects (25 men and 25 women) in each of four age strata (45-49, $50-54,55-59$ and 60-64 years of age at the time of blood sampling). Among the vegetarians from the UK, 65 of the 100 men selected were vegans (eating no animal products) and 35 were lacto-vegetarians (eating no meat or meat products); 88 of the 99 women selected were vegans and 11 were lacto-vegetarians. Both groups were combined and are designated in the text as UK vegetarians.

For France, where only women were included in the EPIC study, only 100 subjects were selected. Excluding France from the multivariate regression analyses for total plasma carotene level did not change gender as a predictor of carotenoid levels. There were differences in age groups for participants in the Danish, Umeå and Greek cohorts. In the Danish cohort, participants were 50 years and older at recruitment, so equal numbers were selected in the three highest age strata. In the Umeå cohort, participants were recruited in the year of their 50th or 60th birthday, and equal numbers of both ages were included in this study. In Greece, there were fewer subjects in the highest age category, compensated for by more in the youngest age strata.

As far as possible, equal numbers of subjects were selected for each season at which their blood sample was collected. In total, 3089 subjects were selected for participation in the study. Four subjects had missing aliquots, and 42 subjects were excluded because of laboratory and other technical reasons, including 23 subjects that were run in one batch with incorrect readings. Thus, the current analyses include 3043 subjects: 1464 men and 1579 women. In the regression analyses, we excluded individuals with missing smoking information, and the final number of subjects available for these analyses was 3011. 


\section{Blood collection}

When study participants visited the local study centre for completion of questionnaires and anthropometric measurements, a 30-ml peripheral blood sample was drawn in three 10-ml Safety Monovettes (Sarstedt, Nümbrecht, Germany), with participants mostly nonfasting. One of the three syringes did not contain anticoagulant, whereas the other two contained $1 \mathrm{ml}$ of $3.13 \%$ trisodium citrate as anticoagulant. Filled syringes were kept at $5-10^{\circ} \mathrm{C}$, protected from light, and transferred to a central laboratory for further processing and aliquoting. After centrifugation at $1500 \boldsymbol{g}$ for $20 \mathrm{~min}$, blood fractions (serum, plasma, buffy coat and red blood cells) were aliquoted into heat-sealed $0.5-\mathrm{ml}$ plastic straws, using a semi-automatic machine (CBS-IMV Technologies, Paris, France). Samples were initially frozen at $-80^{\circ} \mathrm{C}$ in a horizontal position in order to prevent concentration gradients, and then transferred into liquid nitrogen $\left(-196^{\circ} \mathrm{C}\right)$. The 28 aliquots obtained from each subject were divided into two identical series of 14 straws. One series was stored locally in the study centre, and the other was shipped in dry ice or liquid nitrogen to the central biorepository at IARC in Lyon, France. Several centres centralised blood processing in one laboratory, and samples were shipped overnight in cool packs (France, Bilthoven) or at ambient temperature (UK vegetarians) from the blood collection site to the site of blood processing and freezing. Carotenoids are little affected by short-term storage and transport as whole blood ${ }^{19,20}$. In Denmark, Umeå and Malmö, blood was collected using different but comparable techniques because these centres joined EPIC after they had already collected the blood samples. Samples were stored in nitrogen vapour (approximately $-150^{\circ} \mathrm{C}$ ) in Denmark and in freezers at $-80^{\circ} \mathrm{C}$ in the Swedish centres. Subjects gave informed consent at the time of data and blood collection, in accordance with local and IARC ethical committee requirements.

\section{Laboratory analyses}

Aliquots of citrated plasma were extracted from the central biorepository and arranged in batches containing plasma from one subject from each participating centre. Samples were stored in liquid nitrogen $\left(-196^{\circ} \mathrm{C}\right)$. On the day of analysis, aliquots were rapidly thawed at room temperature (the large area/volume ratio of the CBS straws ensures a rapid temperature shift). Samples $(200 \mu \mathrm{l})$ were analysed for carotenoids by reversed-phase high-performance liquid chromatography (HPLC; HPLC-1100 system, Hewlett Packard) following a method based on that of Steghens et al. $^{21}$. Samples were extracted with $800 \mu \mathrm{l}$ of hexane after mixing for $30 \mathrm{~min}$, and mobile phases were concentrated with $1 \mathrm{mll}^{-1}$ of triethylamine.

Samples were analysed in groups of the same sex and age category (45-49, 50-54, 55-59 or 60-64 years), in randomised order for region of residence of subjects. One aliquot from a standard quality control sample was analysed every day and injected at the beginning, middle and end of each series. Analytical columns for HPLC were changed after approximately 1100 injections. In total, five different sets of columns were used during the study. Calibration curves were made once a week, and the standard mixture for calibration was renewed once. Chromatograms were integrated automatically by the system (Chemstation version 6.4; Hewlett Packard, Les Ullis, France) but individually controlled by three different laboratory technicians. Peaks for carotenoids that were under the detection limits were set to zero, while peaks that could not be detected because of technical problems were excluded. Results for six plasma carotenoids are presented in this paper. Plasma concentrations in subjects from Sweden (Malmö and Umeå) were multiplied by 0.83 in order to obtain dilution levels for these heparin plasma samples comparable to the citrated plasma used in the core EPIC cohorts. This dilution factor was based on the hypothesis that, on average, the haematocrit was 0.45 and that, after centrifugation of the blood with anticoagulant, all citrate was in the plasma. Between-day coefficients of variation in concentrations of average population levels and over the entire period of analysis (11 months) were less than 7.6\% except for zeaxanthin (16.5\%). No significant between day drift was observed.

\section{Statistical methods}

Data were analysed using the SAS System for Windows, Release 8.0 (SAS Institute, Cary NC, USA). Since the means and the medians were very similar $(r=0.94-0.99)$, the means and standard deviations are presented for nontransformed data for descriptive purposes. The two-sided Wilcoxon rank-sum test for non-parametric data was used for comparison of concentrations between sexes. The variability in plasma carotenoid concentrations that could be explained by the variables of region (16 regions), gender, season, age at blood collection (in years), body mass index (BMI; $\mathrm{kg} \mathrm{m}^{-2}$ ), alcohol intake $\left(\mathrm{g} \mathrm{day}^{-1}\right)$, smoking status (non-smoker, previous smoker, current smoker), fasting status at the time of blood collection (less than $8 \mathrm{~h}$ or $8 \mathrm{~h}$ and more since fasting), storage time since blood sampling, column and lifetime of column, duration of calibration standard mixture and laboratory technician were investigated with multivariate regression analysis using GLM procedures in SAS. The plasma carotenoid levels were log-transformed. Partial $R^{2}$ is the sum of squares of an independent variable given other independent variables in the model divided by the residual sum of squares of the model excluding that independent variable and then multiplying by 100 to get a percentage ${ }^{22}$. The direction of the association in the model is not calculated by the partial $R^{2}$ results and is not of interest to us since several variables, such as region and season, are not ordered categories. $R^{2}$ for the model was calculated by dividing the uncorrected total sum of squares by the corrected total sum of squares of the model. 
Because of the difference in their age groups, we excluded the Danish, Umeå and Greek regions from secondary multivariate regression analyses to assess the impact of the age variables in the model and found only a slight increase of $0.2 \%$ prediction in the variability of total carotenoid level. To assess any possible bias being introduced by the use of heparin plasma samples in Malmö and Umeå, we carried out secondary analyses and excluded them from the regression model, but this lowered the contribution of only the variable 'region' to the total plasma carotenoids level while the other variables did not change appreciably. The lower contribution of region is expected, since both centres are in the most northern part of Europe, and excluding them is expected to reduce the variability in carotenoid levels explained by region of residence.

\section{Results}

Some characteristics of the study subjects are presented in Table 1. Mean BMI of the participants varied substantially between regions. The highest values were in the regions of Spain, and the lowest values were among UK vegetarians. Mean sample storage time for regions also varied from 1.7 to 5.9 years. Alcohol intake was substantially higher among men than among women in almost all regions (Table 1).

The mean of the sum of the six measured carotenoids $(\alpha$-carotene, $\beta$-carotene, $\beta$-cryptoxanthin, lycopene, lutein and zeaxanthin) varied twofold between regions in men and women $\left(1.35 \mu_{\mathrm{moll}}{ }^{-1}\right.$ for men in Malmö vs. $2.79 \mu \mathrm{mol}^{-1}$ for men in Ragusa/Naples; $1.61 \mu \mathrm{moll}^{-1}$ for women in The Netherlands vs. $3.52 \mu \mathrm{moll}^{-1}$ in Ragusa/ Naples) (Table 2). Mean carotenoid levels by region showed broader distributions; Italian regions, Athens and UK vegetarians had the highest lycopene and lutein levels while $\beta$ - and $\alpha$-carotenes were highest among UK vegetarians and in Heidelberg, and $\beta$-cryptoxanthin levels were higher in the Spanish regions. Figure 1 shows lycopene levels among men and women as an example of the variability of individual carotenoids between regions. Mean concentration of individual carotenoids varied up to fourfold ( $\alpha$-carotene: $0.06 \mu \mathrm{moll}^{-1}$ for men in Murcia vs. $0.25 \mu \mathrm{moll}^{-1}$ for vegetarian men living in the UK). $\beta$ Cryptoxanthin also varied several-fold between regions for both men and women (mean level for men: $0.11 \mu \mathrm{moll}^{-1}$ in Denmark vs. $0.42 \mu \mathrm{moll}^{-1}$ in Granada; mean level for women: $0.20 \mu \mathrm{moll}^{-1}$ in Malmö vs. $0.53 \mu \mathrm{mol}^{-1}$ in Ragusa/Naples). Lycopene was quantitatively the most important carotenoid, followed by

Table 1 Mean and standard deviation (SD) of body mass index (BMI; $\mathrm{kg} \mathrm{m}^{-2}$ ), age (years), alcohol intake $\left(\mathrm{g} \mathrm{day}^{-1}\right)$ and storage of plasma samples (years) for EPIC study subjects in 16 regions of Europe. European Prospective Investigation into Cancer and Nutrition

\begin{tabular}{|c|c|c|c|c|c|c|c|c|c|}
\hline \multirow[b]{2}{*}{ Region } & \multirow[b]{2}{*}{ Gender } & \multicolumn{2}{|c|}{ BMI } & \multicolumn{2}{|c|}{ Age } & \multicolumn{2}{|c|}{ Alcohol intake } & \multicolumn{2}{|c|}{ Sample storage } \\
\hline & & Mean & SD & Mean & SD & Mean & SD & Mean & SD \\
\hline \multirow[t]{2}{*}{ Varese/Turin } & Male & 26.0 & 2.8 & 53.8 & 5.8 & 26.8 & 22.6 & 3.3 & 1.1 \\
\hline & Female & 25.6 & 4.1 & 54.1 & 5.5 & 8.0 & 10.8 & 4.3 & 1.1 \\
\hline \multirow[t]{2}{*}{ Florence } & Male & 26.5 & 3.2 & 54.0 & 5.6 & 22.5 & 22.9 & 3.7 & 1.4 \\
\hline & Female & 25.8 & 4.2 & 54.1 & 5.5 & 9.1 & 12.9 & 4.1 & 1.3 \\
\hline \multirow[t]{2}{*}{ Ragusa/Naples } & Male & 27.4 & 3.6 & 53.7 & 5.8 & 12.9 & 14.2 & 4.3 & 0.9 \\
\hline & Female & 27.3 & 4.4 & 53.9 & 5.6 & 5.3 & 7.6 & 4.6 & 0.9 \\
\hline \multirow[t]{2}{*}{ Athens } & Male & 27.5 & 3.0 & 51.4 & 6.1 & 12.9 & 13.8 & 4.1 & 1.0 \\
\hline & Female & 26.7 & 4.0 & 51.8 & 6.3 & 3.6 & 5.4 & 4.5 & 0.8 \\
\hline \multirow[t]{2}{*}{ Granada } & Male & 29.3 & 3.5 & 54.9 & 5.7 & 13.8 & 17.6 & 5.0 & 1.1 \\
\hline & Female & 29.4 & 4.6 & 54.5 & 5.9 & 2.2 & 5.9 & 5.1 & 1.0 \\
\hline \multirow[t]{2}{*}{ Murcia } & Male & 28.4 & 3.4 & 54.5 & 5.8 & 28.2 & 25.0 & 4.7 & 0.9 \\
\hline & Female & 30.4 & 4.4 & 54.4 & 5.6 & 7.0 & 11.4 & 5.3 & 0.7 \\
\hline \multirow[t]{2}{*}{ Northern Spain } & Male & 29.0 & 3.4 & 54.4 & 5.7 & 32.5 & 35.0 & 5.1 & 0.8 \\
\hline & Female & 28.1 & 4.1 & 54.5 & 5.8 & 5.6 & 9.9 & 5.7 & 0.8 \\
\hline France & Female & 24.7 & 4.1 & 54.1 & 5.3 & 11.5 & 11.6 & 2.4 & 0.4 \\
\hline \multirow[t]{2}{*}{ UK vegetarians } & Male & 23.1 & 2.8 & 54.8 & 5.8 & 9.9 & 14.0 & 3.5 & 0.9 \\
\hline & Female & 22.5 & 3.4 & 55.0 & 5.8 & 3.9 & 6.0 & 4.0 & 1.0 \\
\hline \multirow[t]{2}{*}{ Cambridge } & Male & 25.6 & 2.8 & 54.2 & 5.9 & 13.2 & 16.8 & 2.8 & 1.0 \\
\hline & Female & 25.0 & 3.9 & 54.0 & 5.4 & 7.0 & 12.5 & 3.2 & 0.8 \\
\hline \multirow[t]{2}{*}{ Potsdam } & Male & 27.5 & 3.6 & 54.1 & 5.7 & 21.5 & 18.4 & 1.7 & 0.4 \\
\hline & Female & 25.6 & 3.7 & 54.1 & 5.9 & 8.3 & 9.3 & 2.5 & 0.4 \\
\hline \multirow[t]{2}{*}{ Heidelberg } & Male & 26.8 & 3.5 & 54.5 & 5.5 & 23.6 & 20.7 & 1.8 & 0.6 \\
\hline & Female & 26.0 & 5.0 & 54.4 & 5.3 & 12.2 & 13.8 & 2.3 & 0.7 \\
\hline \multirow{2}{*}{ The Netherlands } & Male & 26.5 & 3.6 & 55.0 & 5.8 & 17.9 & 20.5 & 2.6 & 0.7 \\
\hline & Female & 26.1 & 3.9 & 54.6 & 5.7 & 6.9 & 14.4 & 3.3 & 0.7 \\
\hline \multirow[t]{2}{*}{ Denmark } & Male & 26.6 & 3.4 & 56.9 & 4.3 & 26.4 & 23.4 & 2.2 & 0.3 \\
\hline & Female & 25.8 & 4.8 & 56.9 & 4.2 & 12.5 & 11.8 & 2.8 & 0.3 \\
\hline \multirow[t]{2}{*}{ Malmö } & Male & 26.3 & 3.4 & 54.4 & 5.0 & 16.3 & 15.2 & 5.9 & 1.0 \\
\hline & Female & 25.4 & 4.5 & 54.2 & 5.6 & 8.2 & 9.2 & 5.0 & 1.3 \\
\hline \multirow[t]{2}{*}{ Umeå } & Male & 26.2 & 3.5 & 54.6 & 5.0 & 5.6 & 4.8 & 4.5 & 1.2 \\
\hline & Female & 25.5 & 3.7 & 54.6 & 5.0 & 2.3 & 2.6 & 5.0 & 1.2 \\
\hline
\end{tabular}


Table 2 Mean and standard deviation (SD) of plasma carotenoid levels $\left(\mu \mathrm{molI}^{-1}\right.$ ) in EPIC study subjects in 16 regions of Europe. European Prospective Investigation into Cancer and Nutrition

\begin{tabular}{|c|c|c|c|c|c|c|c|c|c|c|c|c|c|c|c|c|}
\hline \multirow[b]{2}{*}{ Region } & \multirow[b]{2}{*}{ Gender } & \multirow[b]{2}{*}{$n$} & \multicolumn{2}{|c|}{$\alpha$-Carotene } & \multicolumn{2}{|c|}{$\beta$-Carotene } & \multicolumn{2}{|c|}{$\begin{array}{l}\beta \text {-Crypto- } \\
\text { xanthin }\end{array}$} & \multicolumn{2}{|c|}{ Lycopene } & \multicolumn{2}{|c|}{ Lutein } & \multicolumn{2}{|c|}{ Zeaxanthin } & \multicolumn{2}{|c|}{ Total } \\
\hline & & & Mean & SD & Mean & SD & Mean & SD & Mean & SD & Mean & SD & Mean & SD & Mean & SD \\
\hline \multirow[t]{2}{*}{ Varese/Turin } & Male & 99 & 0.15 & 0.11 & 0.42 & 0.25 & 0.32 & 0.18 & 1.03 & 0.43 & 0.60 & 0.24 & 0.13 & 0.06 & 2.64 & 0.83 \\
\hline & Female & 99 & 0.23 & 0.21 & 0.62 & 0.36 & 0.48 & 0.33 & 0.90 & 0.37 & 0.68 & 0.35 & 0.13 & 0.06 & 3.04 & 1.10 \\
\hline \multirow[t]{2}{*}{ Florence } & Male & 97 & 0.12 & 0.10 & 0.39 & 0.21 & 0.26 & 0.23 & 1.01 & 0.37 & 0.56 & 0.21 & 0.11 & 0.06 & 2.44 & 0.75 \\
\hline & Female & 99 & 0.16 & 0.12 & 0.55 & 0.33 & 0.35 & 0.26 & 0.90 & 0.36 & 0.66 & 0.27 & 0.11 & 0.06 & 2.73 & 0.92 \\
\hline \multirow[t]{2}{*}{ Ragusa/Naples } & Male & 92 & 0.08 & 0.12 & 0.39 & 0.22 & 0.31 & 0.22 & 1.29 & 0.46 & 0.61 & 0.26 & 0.11 & 0.05 & 2.79 & 0.81 \\
\hline & Female & 100 & 0.19 & 0.19 & 0.67 & 0.36 & 0.53 & 0.39 & 1.32 & 0.46 & 0.70 & 0.28 & 0.11 & 0.04 & 3.52 & 1.08 \\
\hline \multirow[t]{2}{*}{ Athens } & Male & 95 & 0.08 & 0.07 & 0.40 & 0.21 & 0.33 & 0.22 & 0.90 & 0.38 & 0.51 & 0.21 & 0.11 & 0.04 & 2.31 & 0.71 \\
\hline & Female & 99 & 0.13 & 0.10 & 0.53 & 0.24 & 0.44 & 0.32 & 0.87 & 0.47 & 0.58 & 0.25 & 0.10 & 0.05 & 2.66 & 0.90 \\
\hline \multirow[t]{2}{*}{ Granada } & Male & 97 & 0.07 & 0.06 & 0.24 & 0.13 & 0.42 & 0.35 & 0.69 & 0.40 & 0.40 & 0.16 & 0.10 & 0.04 & 1.90 & 0.68 \\
\hline & Female & 100 & 0.11 & 0.09 & 0.36 & 0.19 & 0.48 & 0.38 & 0.69 & 0.33 & 0.39 & 0.17 & 0.10 & 0.04 & 2.13 & 0.80 \\
\hline \multirow[t]{2}{*}{ Murcia } & Male & 99 & 0.06 & 0.06 & 0.25 & 0.14 & 0.35 & 0.24 & 0.66 & 0.30 & 0.37 & 0.17 & 0.11 & 0.05 & 1.79 & 0.63 \\
\hline & Female & 98 & 0.11 & 0.07 & 0.38 & 0.19 & 0.52 & 0.35 & 0.74 & 0.35 & 0.42 & 0.18 & 0.11 & 0.05 & 2.28 & 0.74 \\
\hline \multirow[t]{2}{*}{ Northern Spain } & Male & 97 & 0.08 & 0.09 & 0.21 & 0.15 & 0.30 & 0.21 & 0.53 & 0.31 & 0.36 & 0.15 & 0.12 & 0.05 & 1.61 & 0.70 \\
\hline & Female & 100 & 0.10 & 0.08 & 0.28 & 0.14 & 0.47 & 0.29 & 0.43 & 0.29 & 0.35 & 0.14 & 0.11 & 0.04 & 1.74 & 0.63 \\
\hline \multirow[t]{2}{*}{ UK vegetarians } & Male & 99 & 0.25 & 0.25 & 0.53 & 0.47 & 0.19 & 0.16 & 0.98 & 0.45 & 0.38 & 0.17 & 0.09 & 0.05 & 2.42 & 1.02 \\
\hline & Female & 99 & 0.32 & 0.28 & 0.68 & 0.71 & 0.24 & 0.16 & & 0.44 & 0.48 & 0.21 & 0.09 & 0.05 & 2.70 & 1.10 \\
\hline \multirow[t]{2}{*}{ Cambridge } & Male & 98 & 0.16 & 0.10 & 0.41 & 0.23 & 0.14 & 0.10 & 0.72 & 0.30 & 0.26 & 0.12 & 0.06 & 0.04 & 1.76 & 0.54 \\
\hline & Female & 99 & 0.24 & 0.15 & 0.53 & 0.27 & 0.21 & 0.12 & 0.77 & 0.38 & 0.30 & 0.11 & 0.07 & 0.03 & 2.11 & 0.73 \\
\hline \multirow[t]{2}{*}{ Potsdam } & Male & 98 & 0.11 & 0.07 & 0.37 & 0.23 & 0.17 & 0.12 & 0.60 & 0.30 & 0.27 & 0.13 & 0.07 & 0.03 & 1.58 & 0.52 \\
\hline & Female & 99 & 0.23 & 0.24 & 0.64 & 0.44 & 0.27 & 0.18 & 0.69 & 0.33 & 0.36 & 0.15 & 0.08 & 0.03 & 2.26 & 0.93 \\
\hline \multirow[t]{2}{*}{ Heidelberg } & Male & 99 & 0.17 & 0.18 & 0.48 & 0.62 & 0.16 & 0.10 & 0.62 & 0.31 & 0.29 & 0.12 & 0.08 & 0.04 & 1.79 & 0.94 \\
\hline & Female & 99 & 0.22 & 0.21 & 0.65 & 0.64 & 0.25 & 0.18 & 0.54 & 0.25 & 0.39 & 0.17 & 0.10 & 0.05 & 2.14 & 1.00 \\
\hline \multirow[t]{2}{*}{ The Netherlands } & Male & 97 & 0.08 & 0.06 & 0.29 & 0.20 & 0.17 & 0.14 & 0.54 & 0.33 & 0.28 & 0.12 & 0.07 & 0.03 & 1.42 & 0.59 \\
\hline & Female & 99 & 0.12 & 0.08 & 0.37 & 0.28 & 0.27 & 0.18 & 0.47 & 0.26 & 0.32 & 0.12 & 0.08 & 0.03 & 1.61 & 0.60 \\
\hline \multirow[t]{2}{*}{ Denmark } & Male & 99 & 0.15 & 0.19 & 0.31 & 0.26 & 0.11 & 0.10 & 0.58 & 0.34 & 0.28 & 0.13 & 0.05 & 0.03 & 1.47 & 0.73 \\
\hline & Female & 98 & 0.22 & 0.18 & 0.47 & 0.38 & 0.23 & 0.21 & 0.53 & 0.29 & 0.34 & 0.14 & 0.07 & 0.04 & 1.86 & 0.84 \\
\hline \multirow[t]{2}{*}{ Malmö } & Male & 99 & 0.11 & 0.11 & 0.30 & 0.29 & 0.13 & 0.09 & 0.46 & 0.24 & 0.28 & 0.13 & 0.06 & 0.03 & 1.35 & 0.61 \\
\hline & & 97 & 0.20 & 0.22 & 0.54 & 0.73 & 0.20 & 0.19 & 0.52 & 0.27 & 0.28 & 0.12 & 0.06 & 0.04 & 1.80 & 1.08 \\
\hline \multirow[t]{2}{*}{ Umeå } & Male & 99 & 0.15 & 0.11 & 0.37 & 0.23 & 0.14 & 0.10 & 0.56 & 0.37 & 0.27 & 0.11 & 0.05 & 0.02 & 1.53 & 0.59 \\
\hline & Female & 99 & 0.29 & 0.24 & 0.66 & 0.73 & 0.24 & 0.16 & 0.44 & 0.25 & 0.31 & 0.13 & 0.06 & 0.03 & 1.99 & 1.02 \\
\hline
\end{tabular}

$\beta$-carotene, while $\alpha$-carotene and zeaxanthin levels were lowest compared with the other carotenoids.

Women had significantly higher total carotenoid levels in all regions than men (Table 2). Using the Wilcoxon signed-ranks test, all of these differences reached statistical significance except in northern Spain. For individual plasma carotenoids, women had higher $\beta$-carotene, $\alpha$-carotene and $\beta$-cryptoxanthin than did men within each region. For lycopene, men had higher levels than did women in 10 regions, and women had higher levels in six regions. The higher lycopene levels among men compared with women reached statistical significance in Florence, northern Spain and Umeå. For lutein and zeaxanthin, women had higher levels than did men in most regions.

In multivariate regression analyses for total carotenoid level, region was the most important significant predictor (partial $R^{2}=27.3 \%, P<0.0001$ ) for carotenoid level after adjustment for other covariates of gender, season, age at blood collection, BMI, alcohol intake and smoking status. The overall $R^{2}$ for the model was $0.35(P<0.0001)$. We excluded from the final model the variables of fasting status, storage time after blood sampling, column and lifetime of column, duration of calibration standard mixture and laboratory technician, because they were mostly non-significant and did not contribute more than $0.2 \%$ variability to any of the individual carotenoids. BMI was the second most important predictor (partial $\left.R^{2}=5.2 \%, \quad P<0.0001\right)$ followed by smoking status (partial $R^{2}=2.8 \%, \quad P<0.0001$ ), gender (partial $R^{2}=2.7 \%, P<0.0001$ ), season (partial $R^{2}=0.3 \%$, $P<0.04$ ) and alcohol intake (partial $R^{2}=0.2 \%$, $P<0.01)$. The age variable was non-significant in the model. For individual carotenoids, the multivariate regression analyses generally followed a similar pattern to the total carotenoids where region was the most important predictor (Table 3). However, there were differences in the contribution of the predictors to the variability of $\beta$-cryptoxanthin and lycopene, where season was the second most important independent predictor while BMI was not an important predictor. Age was the second most important predictor for zeaxanthin.

\section{Discussion}

This is the first large cross-sectional study analysing plasma carotenoid levels in several European populations, with all of the analyses being carried out in a single laboratory using standardised protocols for the analytical methods. Considerable variations in plasma concentrations of six carotenoids were found between 16 regions in nine European countries. Region was the most important predictor of plasma carotenoids in regression analyses. 
a)

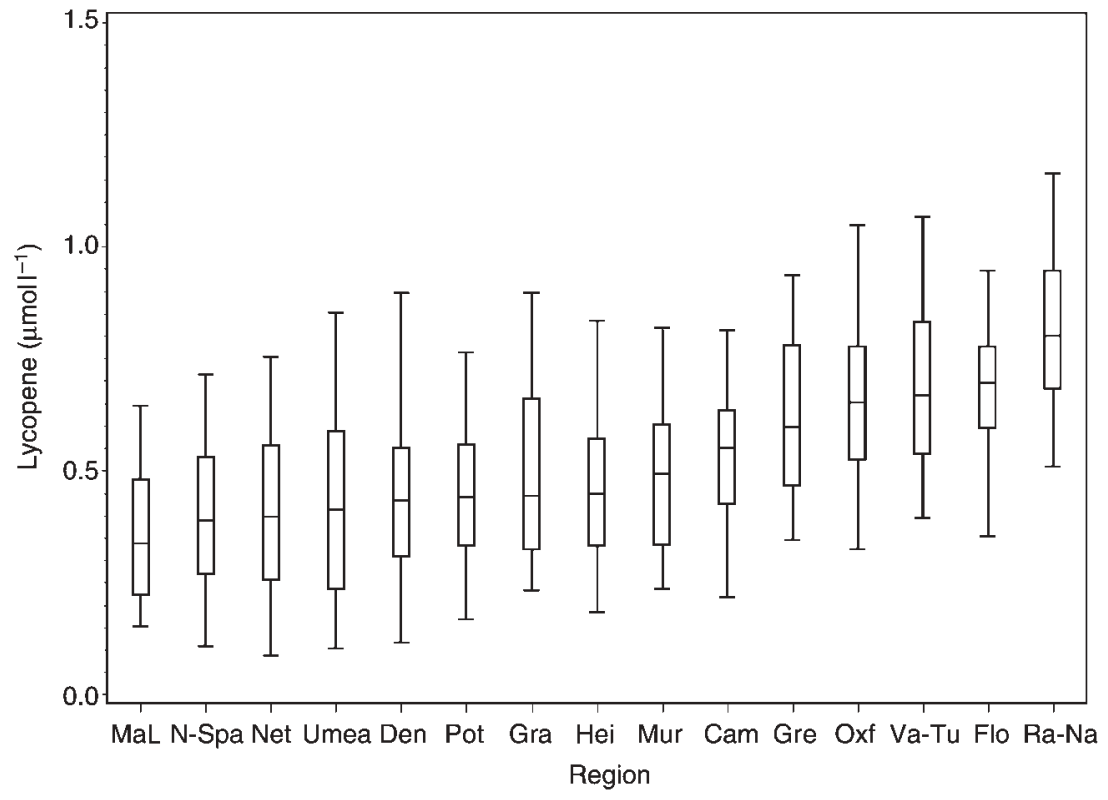

b)

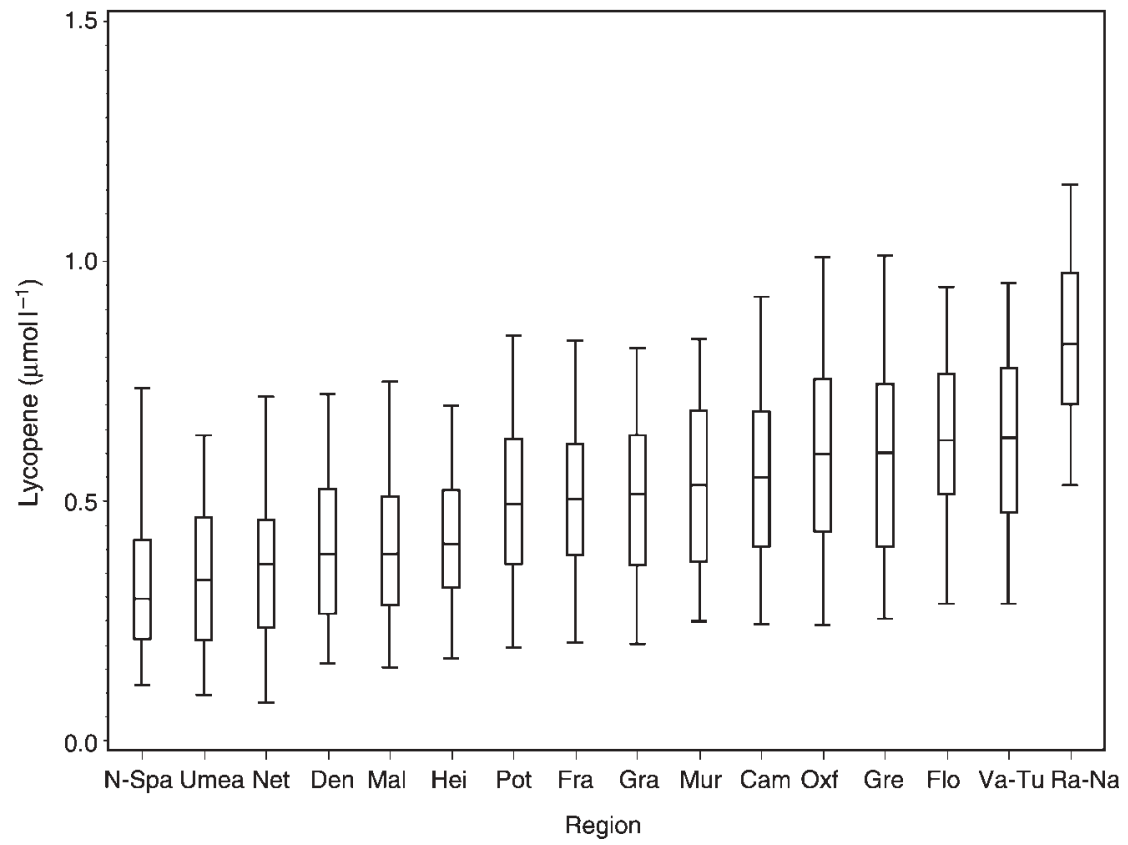

Fig. 1 Box plots of plasma lycopene levels for men (a) and women (b) according to region as an example of the variability of individual carotenoids among the 16 regions participating in EPIC (European Prospective Investigation into Cancer and Nutrition). Whiskers are the range of values (excluding outliers), boxes are $25-75 \%$, middle line is median. Mal - Malmö; N-Spa - northern Spain; Net - The Netherlands; Umea - Umeå; Den - Denmark; Pot - Potsdam; Gra - Granada; Hei - Heidelberg; Mur - Murcia; Cam - Cambridge; Gre - Greece; Oxf - UK vegetarians; Va-Tu - Varese/Turin; Flo - Florence; Ra-Na - Ragusa/Naples

We found higher concentrations of total carotenoids in southern European regions than in northern Europe. UK vegetarians had carotenoid levels close to those found in southern European regions, confirming the finding that vegetarians consume qualitatively and quantitatively more fruit and vegetables and have higher blood carotenoid levels than comparable non-vegetarians ${ }^{23}$. Levels of individual carotenoids were also generally higher in the southern regions, except for $\alpha$ - and $\beta$-carotenes, which showed no clear north-south difference.
Serum carotenoids have also been assessed in five European countries by Olmedilla et $a l^{16}$, who similarly reported wide variability between northern and southern Europe. Spain had the highest $\beta$-cryptoxanthin levels, while lutein and zeaxanthin were higher in south Europe (France and Spain) than in the north (Northern Ireland and the Republic of Ireland). Similar to our study, there was no clear north-south trend for $\alpha$ - and $\beta$-carotenes.

Fruit and vegetables are the main dietary sources of carotenoids for humans, but correlations between intake 
Table 3 Multiple regression analyses of predictors of log-transformed plasma carotenoid levels in Europe $(n=3011)$

\begin{tabular}{|c|c|c|c|c|c|c|c|c|c|c|c|c|c|}
\hline \multirow[b]{2}{*}{ Variable } & \multirow[b]{2}{*}{ DF } & \multicolumn{2}{|c|}{$\alpha$-Carotene } & \multicolumn{2}{|c|}{$\beta$-Carotene } & \multicolumn{2}{|c|}{$\beta$-Cryptoxanthin } & \multicolumn{2}{|c|}{ Lycopene } & \multicolumn{2}{|c|}{ Lutein } & \multicolumn{2}{|c|}{ Zeaxanthin } \\
\hline & & $\begin{array}{l}\text { Partial } \\
R^{2}(\%)\end{array}$ & $P$-value* & $\begin{array}{l}\text { Partial } \\
R^{2}(\%)\end{array}$ & $P$-value* & $\begin{array}{l}\text { Partial } \\
R^{2}(\%)\end{array}$ & $P$-value* & $\begin{array}{l}\text { Partial } \\
R^{2}(\%)\end{array}$ & $P$-value* & $\begin{array}{l}\text { Partial } \\
R^{2}(\%)\end{array}$ & $P$-value* & $\begin{array}{l}\text { Partial } \\
R^{2}(\%)\end{array}$ & $P$-value* \\
\hline Region & 15 & 9.8 & $<0.0001$ & 7.8 & $<0.0001$ & 23 & $<0.0001$ & 29 & $<0.0001$ & 37 & $<0.0001$ & 26 & $<0.0001$ \\
\hline BMI & 1 & 3.5 & $<0.0001$ & 4.2 & $<0.0001$ & 1.8 & $<0.0001$ & 0.8 & $<0.0001$ & 2.7 & $<0.0001$ & 1.5 & $<0.0001$ \\
\hline Gender & 1 & 3.4 & $<0.0001$ & 3.7 & $<0.0001$ & 2.8 & $<0.0001$ & 0.2 & 0.004 & 1.9 & $<0.0001$ & 0.3 & $<0.003$ \\
\hline Season & 3 & 0.4 & 0.006 & 0.8 & $<0.0001$ & 4.1 & $<0.0001$ & 2.9 & $<0.0001$ & 0.8 & $<0.0001$ & 1.4 & $<0.0001$ \\
\hline Age & 1 & 0.4 & $<0.0008$ & 0.2 & 0.02 & & NS & 0.5 & $<0.0003$ & 1.1 & $<0.0001$ & 3.2 & $<0.0001$ \\
\hline Alcohol intake & 1 & 0.3 & $<0.003$ & 0.6 & $<0.0001$ & 0.5 & $<0.0003$ & & NS & 0.2 & 0.03 & 0.3 & 0.005 \\
\hline Smoking status & 2 & 1.4 & $<0.0001$ & 1.8 & $<0.0001$ & 2.6 & $<0.0001$ & & NS & 1.6 & $<0.0001$ & 0.9 & $<0.0001$ \\
\hline Model $R^{2}$ & 24 & \multicolumn{2}{|c|}{0.25} & \multicolumn{2}{|c|}{0.24} & \multicolumn{2}{|c|}{0.34} & \multicolumn{2}{|c|}{0.32} & \multicolumn{2}{|c|}{0.40} & \multicolumn{2}{|c|}{0.29} \\
\hline
\end{tabular}

$\mathrm{DF}$ - degrees of freedom; BMI - body mass index; NS - not significant $(P>0.05)$.

${ }^{*} P$-values of $F$-test on type III sum of squares estimate.

and plasma levels of carotenoids are variable and range from 0.1 to $0.7^{24}$. This variability may be attributed to the bioavailability of carotenoids from fruits and vegetables, which may vary with cooking and processing ${ }^{25-28}$. On the other hand, the bioavailability of carotenoids that are not bound to protein complexes, such as those in supplements or food colorants, which are used increasingly in certain countries, is high ${ }^{29}$. The inter-individual variability in bioavailability and absorption of carotenoids is difficult to assess in large epidemiological studies. It is assumed that the difference in bioavailability and absorption is random, and did not bias levels of carotenoids from the different countries to one direction or the other.

Season is an important factor in relation to carotenoid levels in blood, because dietary sources of these carotenoids are likely to vary by season. Seasonal factors such as light and heat may affect the carotenoid content of specific fruits and vegetables. We attempted to stratify by season in the selection of subjects, and we further adjusted for seasonal variations in the regression analyses. Although season was statistically significant in the regression model for all carotenoids, it was a more important predictor for lycopene and $\beta$-cryptoxanthin compared with the other variables in the model. Seasonal variations in some serum carotenoids have been observed by some investigators ${ }^{30-33}$ but not by others ${ }^{34,35}$. The influence of season on intake of fruits and vegetables has decreased in industrialised countries because of the availability of these products all year long. Nevertheless, it is likely that seasonal fruits and vegetables that are the main source of certain carotenoids (tomatoes for lycopene, citrus fruits for $\beta$-cryptoxanthin) will have a significant effect on blood levels. The season of collection of a blood sample from study participants thus has to be taken into consideration in studies assessing carotenoids among different populations.

Women in our study had higher plasma levels of carotenoids than men, except for lycopene. This is in agreement with data reported earlier ${ }^{31,33}$. This was also found in EURAMIC (EURopean study on Antioxidants, Myocardial Infarction and Cancer of the breast), where adipose tissue carotenoid levels were measured among 986 subjects $^{36}$. The difference between the sexes may be due to quantitative and qualitative (relative to energy intake) differences in intake, absorption and metabolism. Hormonal changes during the menstrual cycle have been shown to affect carotenoid serum levels in women ${ }^{37}$. In regression analyses, however, gender was not as important as region or BMI and was weakly predictive for plasma lycopene and zeaxanthin. BMI has been found to be negatively associated with plasma and adipose tissue carotenoid levels ${ }^{38-41}$. In our regression analyses it was an important predictor for plasma carotenoid levels, second only to region. It is not fully understood why this variable could be related to levels of carotenoids, but one possibility is that people with high BMI are less likely to consume fruits and vegetables, the main sources of plasma carotenoids. According to Shils et ll $^{42}$, distribution of carotenoids in adipose tissue reflects that in plasma and there is no differential tissue distribution for individual carotenoids other than lutein/zeaxanthin in the macula of the eye and $\beta$-carotene in the pineal gland.

Smoking and alcohol intake are thought to influence carotenoid levels in blood ${ }^{40,43-46}$. Smoking is negatively related to carotenoid levels, with smoking cessation increasing plasma levels of carotenoids ${ }^{47}$, while alcohol is believed to increase serum carotenoid levels ${ }^{43,44}$. In our analyses, however, both smoking and alcohol contributed little to the variability in carotenoid levels, even though there was variability in smoking habits and alcohol intake across regions. Except for zeaxanthin, age was not an important predictor in the regression analyses, which is most probably due to the stratified selection of samples based on age in order to enable comparison between subjects from different countries. There was limited variability in age among our subjects, as shown in Table 1. Others ${ }^{33}$ have found age to be positively correlated with all carotenoids, except for $\beta$-cryptoxanthin, while several studies found age to be negatively associated with lycopene $e^{40,48,49}$.

The use of a standard protocol for collection and storage of blood samples in all regions except Denmark and 
Sweden minimised potential bias. From our analyses, it seemed unlikely that the different storage temperatures between the EPIC study regions affected carotenoid levels. Although there was wide variability in storage time between regions, this did not affect carotenoid levels. Carotenoids have been estimated to be stable for at least 15 years at temperatures below $-70^{\circ} \mathrm{C}^{50}$. Brown et al ${ }^{51}$ found no significant changes in individual or total plasma carotenoids over a 4-h post-prandial period. As plasma in the two Swedish regions was prepared from heparinised blood, we had to apply a dilution coefficient in order to obtain comparable values. Our assumption of an average haematocrit of 0.45 , and the different type of anticoagulant used, may have biased results ${ }^{52}$ for these two cohorts. However, when we excluded both these centres from our analyses the conclusions of the study did not change.

All analyses of carotenoids were carried out in the same laboratory, and between-day coefficients of variation were low. The use of biochemical measurements in large-scale epidemiological samples is feasible only with techniques that are relatively cheap and do not need extended time periods for analyses. Variability in performance of columns, calibration standards and laboratory technicians are among potential sources of bias. However, in our analyses, the inclusion of these parameters in regression analyses indicated that the magnitude of their effect on plasma carotenoid levels was limited in comparison to the effect of region, BMI, gender and the other variables. Differences between columns in completeness of separation between the peaks of lutein and zeaxanthin may explain the higher between-day coefficient of variation for zeaxanthin.

In conclusion, in this study of 16 geographical regions in Europe, region was the most important predictor of plasma levels of six different carotenoids. The rationale of the EPIC study is to take full advantage of the regional variations in both diet and cancer risk. Indeed, there are variations of up to two- or threefold between northern and southern Europe in age-standardised incidence rates of cancers of the colon, breast, ovary and pancreas (more frequent in the North $)^{53}$. Assuming that diet is indeed the most important determinant of plasma carotenoid levels, the results of this cross-sectional study show that dietary habits also vary widely across different regions of Europe. With this considerable heterogeneity in both diet and cancer incidence rates, it should be possible to carry out more powerful studies of relationships between diet, markers of diet and cancer risk.

\section{Acknowledgements}

The EPIC study is supported by the 'Europe Against Cancer' Programme of the European Commission (SANCO); Ligue contre le Cancer (France); Société 3M (France); Mutuelle Générale de l'Education Nationale; Institut National de la Santé et de la Recherche Médicale (INSERM); German Cancer Aid; German Cancer Research
Center; German Federal Ministry of Education and Research; Danish Cancer Society; Health Research Fund (FIS) of the Spanish Ministry of Health; the participating regional governments and institutions of Spain; Cancer Research UK; Medical Research Council, UK; Stroke Association, UK; British Heart Foundation; Department of Health, UK; Food Standards Agency, UK; Wellcome Trust, UK; Greek Ministry of Health; Greek Ministry of Education; Italian Association for Research on Cancer (AIRC); Italian National Research Council; Dutch Ministry of Public Health, Welfare and Sports; Dutch Ministry of Health; Dutch Prevention Funds; LK Research Funds; Dutch ZON (Zorg Onderzoek Nederland); World Cancer Research Fund (WCRF); Swedish Cancer Society; Swedish Scientific Council; and Regional Government of Skane, Sweden.

A.L.V.K. received financial support from APRIFEL, France. The carotenoid standards were gifts from Hoffman-la-Roche, Basle, Switzerland.

The authors would like to thank Béatrice Vozar and David Achaintre for technical assistance with the laboratory measurements, and Bertrand Hémon and Carine Biessy for data management.

\section{References}

1 International Agency for Research on Cancer (IARC). Carotenoids. IARC Handbooks of Cancer Prevention, Vol. 2. Lyon: IARC, 1998.

2 Giovannucci E, Ascherio A, Rimm EB, Stampfer MJ, Colditz GA, Willett WC. Intake of carotenoids and retinol in relation to risk of prostate cancer. Journal of the National Cancer Institute 1995; 87: 1767-76.

3 Giovannucci E. Tomatoes, tomato-based products, lycopene, and cancer: review of the epidemiologic literature. Journal of the National Cancer Institute 1999; 91: 317-31.

4 World Cancer Research Fund/American Institute for Cancer Research (AICR). Food, Nutrition and the Prevention of Cancer, A Global Perspective. Washington, DC: AICR, 1997.

5 Canfield LM, Forage JW, Valenzuela JG. Carotenoids as cellular antioxidants. Proceedings of the Society for Experimental Biology and Medicine 1992; 200: 260-5.

6 Sies H, Stahl W. Vitamins E and C, beta-carotene, and other carotenoids as antioxidants. American Journal of Clinical Nutrition 1995; 62(Suppl.): 1315S-21S.

7 Peto R, Doll R, Buckley JD, Sporn MB. Can dietary betacarotene materially reduce human cancer rates? Nature 1981 290: $201-8$.

8 Tsubono Y, Tsugane S, Gey KF. Plasma antioxidant vitamins and carotenoids in five Japanese populations with varied mortality from gastric cancer. Nutrition and Cancer 1999 ; 34: $56-61$.

9 Hulten K, van Kappel AL, Winkvist A, Kaaks R, Hallmans G, Lenner $\mathrm{P}$, et al. Carotenoids, alpha-tocopherols, and retinol in plasma and breast cancer risk in northern Sweden. Cancer Causes E Control 2001; 12: 529-37.

10 Lu QY, Hung JC, Heber D, Go VL, Reuter VE, Cordon-Cardo $\mathrm{C}$, et al. Inverse associations between plasma lycopene and other carotenoids and prostate cancer. Cancer Epidemiology, Biomarkers \& Prevention 2001; 10: 749-56.

11 Giovannucci E. A review of epidemiologic studies of tomatoes, lycopene, and prostate cancer. Experimental Biology and Medicine 2002; 227: 852-9.

12 Khachik F, Beecher GR, Goli MB, Lusby WR. Separation and 
quantitation of carotenoids in foods. Methods in Enzymology 1992; 213: 347-59.

13 Khachik F, Beecher GR, Goli MB, Lusby WR, Smith JC Jr. Separation and identification of carotenoids and their oxidation products in the extracts of human plasma. Analytical Chemistry 1992; 64: 2111-22.

14 Van het Hof KH, Brouwer IA, West CE, Haddeman E, Steegers-Theunissen RP, van Dusseldorp M, et al. Bioavailability of lutein from vegetables is 5 times higher than that of beta-carotene. American Journal of Clinical Nutrition 1999; 70: 261-8.

15 Irwig MS, El-Sohemy A, Baylin A, Rifai N, Campos H. Frequent intake of tropical fruits that are rich in betacryptoxanthin is associated with higher plasma betacryptoxanthin concentrations in Costa Rican adolescents. Journal of Nutrition 2002; 132: 3161-7.

16 Olmedilla B, Granado F, Southon S, Wright AJ, Blanco I, Gil-Martinez E, et al. Serum concentrations of carotenoids and vitamins $\mathrm{A}, \mathrm{E}$, and $\mathrm{C}$ in control subjects from five European countries. British Journal of Nutrition 2001; 85: $227-38$.

17 Riboli E, Kaaks R. The EPIC Project: rationale and study design. International Journal of Epidemiology 1997; 26(Suppl. 1): S6-14.

18 Slimani N, Kaaks R, Ferrari P, Casagrande C, Clavel-Chapelon $\mathrm{F}$, Lotze $\mathrm{G}$, et al. European Prospective Investigation into Cancer and Nutrition (EPIC) calibration study: rationale, design and population characteristics. Public Health Nutrition 2002; 5: 1125-45.

19 Hankinson SE, London SJ, Chute CG, Barbieri RL, Jones L, Kaplan LA, et al. Effect of transport conditions on the stability of biochemical markers in blood. Clinical Chemistry 1989; 35: 2313-6.

20 Key T, Oakes S, Davey G, Moore J, Edmond LM, McLoone UJ, et al. Stability of vitamins A, C, and E, carotenoids, lipids, and testosterone in whole blood stored at $4^{\circ} \mathrm{C}$ for 6 and 24 hours before separation of serum and plasma. Cancer Epidemiology, Biomarkers \& Prevention 1996; 5: 811-4.

21 Steghens JP, van Kappel AL, Riboli E, Collombel C. Simultaneous measurement of seven carotenoids, retinol and $\alpha$-tocopherol in serum by high-performance liquid chromatography. Journal of Chromatography B 1997; 694: 71-81.

22 Kleinbaum DG, Kupper LL, Muller KE, eds. Applied Regression Analysis and Other Multivariable Methods. Belmont, CA: Duxbury Press, 1988; 151.

23 Rauma AL, Mykkanen H. Antioxidant status in vegetarians versus omnivores. Nutrition 2000; 16: 111-9.

24 Kaaks R, Riboli E, Sinha R. Biochemical markers of dietary intake. In: Toniolo P, Boffetta P, Shuker DEG, Rothman N, Hulka B, Pearce N, eds. Application of Biomarkers in Cancer Epidemiology. International Agency for Research on Cancer (IARC) Scientific Publication No. 142. Lyon: IARC, 1997; $103-26$.

25 Gartner C, Stahl W, Sies H. Lycopene is more bioavailable from tomato paste than from fresh tomatoes. American Journal of Clinical Nutrition 1997; 66: 116-22.

26 Edwards AJ, Nguyen CH, You CS, Swanson JE, Emenhiser C, Parker RS. Alpha- and beta-carotene from a commercial puree are more bioavailable to humans than from boiled-mashed carrots, as determined using an extrinsic stable isotope reference method. Journal of Nutrition 2002; 132: 159-67.

27 Huang C, Tang YL, Chen CY, Chen ML, Chu CH, Hseu CT. The bioavailability of beta-carotene in stir- or deep-fried vegetables in men determined by measuring the serum response to a single ingestion. Journal of Nutrition 2000; 130: $534-40$

28 Rock CL, Lovalvo JL, Emenhiser C, Ruffin MT, Flatt SW, Schwartz SJ. Bioavailability of beta-carotene is lower in raw than in processed carrots and spinach in women. Journal of Nutrition 1998; 128: 913-6.

29 Erdman JW Jr, Bierer TL, Gugger ET. Absorption and transport of carotenoids. Annals of the New York Academy of Sciences 1993; 691: 76-85.

30 Cooney RV, Franke AA, Hankin JH, Custer LJ, Wilkens LR, Harwood PJ, et al. Seasonal variations in plasma micronutrients and antioxidants. Cancer Epidemiology, Biomarkers \& Prevention 1995; 4: 207-15.

31 Olmedilla B, Granado F, Blanco I, Rojas-Hidalgo E. Seasonal and sex-related variations in six serum carotenoids, retinol, and alpha-tocopherol. American Journal of Clinical Nutrition 1994; 60: 106-10.

32 Rautalahti M, Albanes D, Haukka J, Roos E, Gref CG, Virtamo J. Seasonal variation of serum concentrations of betacarotene and alpha-tocopherol. American Journal of Clinical Nutrition 1993; 57: 551-6.

33 Ito Y, Ochiai J, Sasaki R, Suzuki S, Kusuhara Y, Morimitsu Y, et al. Serum concentrations of carotenoids, retinol, and alpha-tocopherol in healthy persons determined by highperformance liquid chromatography. Clinica Chimica Acta 1990; 194: 131-44.

34 Cantilena LR, Stukel TA, Greenberg ER, Nann S, Nierenberg DW. Diurnal and seasonal variation of five carotenoids measured in human serum. American Journal of Clinical Nutrition 1992; 55: 659-63.

35 Zheng S, Ershow AG, Yang CS, Li GY, Li RS, Li H, et al. Nutritional status in Linxian, China: effects of season and supplementation. International Journal for Vitamin and Nutrition Research 1989; 59: 190-9.

36 Virtanen SM, van't Veer P, Kok F, Kardinaal AF, Aro A. Predictors of adipose tissue carotenoid and retinol levels in nine countries. The EURAMIC Study. American Journal of Epidemiology 1996; 144: 968-79.

37 Forman MR, Beecher GR, Muesing R, Lanza E, Olson B, Campbell WS, et al. The fluctuation of plasma carotenoids by phase of the menstrual cycle: a controlled diet study. American Journal of Clinical Nutrition 1996; 64: 559-65.

38 Ascherio A, Stampfer MJ, Colditz GA, Rimm EB, Litin L, Willett WC. Correlations of vitamin A and E intakes with plasma concentrations of carotenoids and tocopherols among American men and women. Journal of Nutrition 1992; 122: 1792-801.

39 Hebert JR, Hurley TG, Hsieh J, Rogers E, Stoddard AM, Sorensen G, et al. Determinants of plasma vitamins and lipids: the Working Well Study [published erratum in American Journal of Epidemiology 1994; 140: 856]. American Journal of Epidemiology 1994; 140: 132-47.

40 Brady WE, Mares-Perlman JA, Bowen P, Stacewicz-Sapuntzakis M. Human serum carotenoid concentrations are related to physiologic and lifestyle factors. Journal of Nutrition 1996; 126: 129-37.

41 Scott KJ, Thurnham DI, Hart DJ, Bingham SA, Day K. The correlation between the intake of lutein, lycopene and betacarotene from vegetables and fruits, and blood plasma concentrations in a group of women aged $50-65$ years in the UK. British Journal of Nutrition 1996; 75: 409-18.

42 Shils ME, Olson JA, Shike M, Ross AC, eds. Modern Nutrition in Health and Disease, 9th ed. Philadelphia, PA: Lippincott Williams \& Wilkins, 1999; 529.

43 Forman MR, Beecher GR, Lanza E, Reichman ME, Graubard BI, Campbell WS, et al. Effect of alcohol consumption on plasma carotenoid concentrations in premenopausal women: a controlled dietary study. American Journal of Clinical Nutrition 1995; 62: 131-5.

44 Ahmed S, Leo MA, Lieber CS. Interactions between alcohol and beta-carotene in patients with alcoholic liver disease. American Journal of Clinical Nutrition 1994; 60: 430-6.

45 Zondervan KT, Ocké MC, Smith HA, Aoki K. Do dietary and supplementary intake of antioxidants differ with smoking 
status? International Journal of Epidemiology 1996; 25 $70-9$.

46 Ito Y, Sasaki S, Suzuki S, Aoki K. Relationship between serum xanthophyll levels and the consumption of cigarettes, alcohol or foods in healthy inhabitants of Japan. International Journal of Epidemiology 1991; 20: 615-20.

47 Polidori MC, Mecocci P, Stahl W, Sies H. Cigarette smoking cessation increases plasma levels of several antioxidant micronutrients and improves resistance towards oxidative challenge. British Journal of Nutrition 2003; 90: 147-50.

48 Vogel S, Contois JH, Tucker KL, Wilson PWF, Schaefer EJ, Lammi-Keefe CJ. Plasma retinol and plasma and lipoprotein tocopherol and carotenoid concentrations in healthy elderly participants of the Framingham Heart Study. American Journal of Clinical Nutrition 1997; 66: 950-8.

49 Michaud DS, Giovannucci EL, Ascherio A, Rimm EB, Forman MR, Sampson L, et al. Associations of plasma carotenoid concentrations and dietary intake of specific carotenoids in samples of two prospective cohort studies using a new carotenoid database. Cancer Epidemiology, Biomarkers E Prevention 1998; 7: 283-90.

50 Comstock GW, Alberg AJ, Helzlsouer KJ. Reported effects of long-term freezer storage on concentrations of retinol, betacarotene, and alpha-tocopherol in serum or plasma summarized. Clinical Chemistry 1993; 39: 1075-8.

51 Brown ED, Rose A, Craft N, Seidel KE, Smith JC Jr. Concentrations of carotenoids, retinol, and tocopherol in plasma, in response to ingestion of a meal. Clinical Chemistry 1989; 35: 310-2.

52 Nierenberg DW. Serum and plasma beta-carotene levels measured with an improved method of high-performance liquid chromatography. Journal of Chromatography 1985; 339: 273-84.

53 Bray F, Sankila R, Ferlay J, Parkin DM. Estimates of cancer incidence and mortality in Europe in 1995. European Journal of Cancer 2002; 38: 99-166. 